\title{
Parâmetros fisiológicos e etológicos do potro recém-nascido, na raça puro-sangue de corrida
}

\section{Ethological and physiological parameters in the thoroughbred newborn foal}

CORAESPONDENCE TO: Mário Kurtz Filho Depantamento de Mortotogie Centro de Cidncias de Saúce Contversidade Federal de Santa Maria 97119-900 - Santa Maria - RS - Brasil o-mail: kurtz Osaigon.cpd.ufsm.br

1 - Departamento de Morfologia Universidade Federal de Santa Maria - AS

2. Haras Santa Maria de Araras São José do Pinhais - PR 3 - Haras Santa Mania de Araras Bagé - RS

4 - Departamento de Clínica Veterinána de Grandes Animais Universidade Federal de Santa Maria - RS

\section{RESUMO}

Foram observados trezentos e noventa partos em éguas da raça Puro-Sangue de Corrida entre julho de 1983 e novembro de 1992 , com a finalidade de se determinar os parâmetros fisiológicos e etológicos relativos ao neonato, Verificou-se que a ruptura do cordão umbilical ocorreu em torno dos 6,2 minutos após o nascimento. O reflexo de sucção manifestou-se em média aos 36 minutos e os potrinhos levantaram pela primeira vez aos 49 minutos. Aqueles que levantaram até 2 horas e 23 minutos após o parto não apresentaram problemas. A $1^{\text {a }}$ mamada ocorreu em média aos 94 minutos pós-parto e 82,55\% dos potros mamaram até 2 horas pós-parto. A eliminação do mecônio ocorreu em 127,4 minutos pós-parto, em média 30 minutos após a $1^{2}$ mamada.

UNITERMOS: Potro, recém-nascido, cordão umbilical, colostro, mecônio

\section{INTRODUÇÃO}

T Tm-se como média que o período de gestação da égua PuroSangue de Corrida é de 338-340 dias (Rossdale; Ricketts ${ }^{17}$. 1980) e alguns autores sugerem que produtos do sexo masculino possuem um período gestacional significativamente maior do que as fêmeas (Ropiha et al. ${ }^{2}, 1969$; Hintz et al. $.^{5}, 1979$ ). Quando se observa o parto na égua alguns fatores devem ser considerados.

O cordão umbilical, conexão entre o feto e a placenta, divide-se em duas porçōes: a primeira é a amniớtica que se estende do umbigo, através da cavidade amniótica, até a alantóide; a segunda é a porção alantoidiana que se estende do âmnion até o alanto-córion. Quando sob tensão esta musculatura vascular lisa entra em espasmos; em algumas espécies, como na equïna, existe um esfíncter, contendo músculos lisos longitudinais e circulares, que enlaçam os vasos do cordãon na sua entrada no abdômen ou. além. na junção do abdômen e âmnion. O comprimento do cordão pernite que o potro naxy̧a com o cordão intacto, permanecendo assim até que a mãe ou o potro se afastem um do outro.

Rossdale; Mahaffey ${ }^{16}$ (1958) verificaram a quantidade de sangue que poderia fluir da placenta quando o cordão umbilical fosse incidido logo após o partoe até 18 minutos após o parto. Quando a incisãoocorreu logo após o parto recolheu-se uma média de 1.020 mililitros $(660)-1.500)$ $\mathrm{ml}$ ). Quando a incisão (xorreu logo após ter cessado a pulsação no cordão umbilical. recolheu-se em média $170 \mathrm{ml}(70-240 \mathrm{ml})$. Estes autores concluíram que, quando ocorre uma ruptura precoce do cordão umbilical, o potro seria privado de $1 .(0)(0)$ a $1.5(x)$ ml de sangue placentário fetal. o que poderia levar à manifestação da síndrome de dexajustamento neonatal. Doarn et al. ${ }^{3}$ (1987) realizaram um estudo para determinar a pre- sença de fluxo sanguíneo umbilical imediatamente no pós-parto e determinar se o corte prematuro do cordão umbilical poderia alterar significativamente os padrōes hematológicos do neonato. Observaram a ausência de fluxo sanguíneo no grupo controle durante os dois primeiros minutos após o parto. não havendo diferença significativa entre $\alpha$ dois grupos quanto à análise hematológica. Concluíram que o cordão umbilical pode ser separado sem nenhum prejuízo ao potro.

O reflexo de sucção parece estar presente dentro de meia a uma hora após o parto. Ele pode ser estimulado pelo contato do focinho e lábios do potro com o focinho da égua ao cheirá-lo ou lambê-lo, ou pelo contato com a sua própria pele ou a da égua. Mahaffey; Rossdale ${ }^{10}$ (1957) observaram que tão $\operatorname{logo}$ o potro nasce diferentes reflexos são por ele apresentados: a respiração ofegante é substituída pela respiração rítmica, com o cordão umbilical ainda intacto. Segue-se a postura em decúbito estemal e a apresenbação do reflexo de suç̧ão. Um reflexo de sucção da fraca intensidade parece estar associado com alguma fraqueza somática, resultante de prematuridade ou septicemia. A intensidade do reflexo de sucção varia durante a evolução da doença. Na doença do potro dorminhoco (Actinobacillus equuli), ele inicialmente suga vigorosamente, mas perde gradualmente a sua habilidade para sugar, enquanto o seu estado se agrava (Rossdale $\left.{ }^{15}, 1968 \mathrm{~b}\right)$.

A capacidade de levantar-se é manifestada pela habilidade de elevar a cabeça e de rodar sobre o esterno, com os membros anteriores estendidos ou flexionados. Estes atos representam o estágio ini-cial do processode se levantar. A causa mais comum de falha na tentativa de se levantar pela primeira vez é fraqueza muscular e dificuldade na coordenação dos movimentos da cabeça, troncoe membrox. Roxiscdale ${ }^{13}$ (1967) e Campitelli et al..$^{2}(1982 / 1983)$ observaram esta (ocorrência em tomo de uma hora 
KUJRTZ FILHO. M : DEPRÁ. N.M.; ALDA, J.L.; CASTRO, I.N.; CORTE, F.D.; SILVA. C.A.M. Parâmerros físiológicos c ctológicos do potro recém-nascido, ná rą̧a puru-sunguc de corrida. Braz. J. vet. Res. anim. Scí., São Paulo, v.34, n.2, p. I03-108, 1997

após o parto. Alguns autores atribuíram à diferença de peso entre potros como o principal fator para alguns potrinhos levantarem mais precocemente do que outros (Whitwell; Jeffcott ${ }^{21}$, 1975). Campitelli et al. ${ }^{2}$ (1982/ 1983) observou que as fềmeas eram mais leves e levantaram mais codo do que os machos. Ao nascimento, o potro a termo pesa ao redor de $10 \%$ do peso da mãe e potros são um pouco mais pesados do que potrancas (Plath. 1978). Observou-se que os potros foram mais pesados do que as potrancas ao nascimento e as diferenças aumentaram com a idade, nos primeiros meses de vida (Hintz et al. $\left.{ }^{6}, 1979\right)$. Rossdale ${ }^{14}$ (1968a) efetuou uma comparação entre potros nascidos de gestações simples e potros de gestacōes gemelares que permaneceram vivos (em ambos os sexos); o peso módio dos potros de gestações simples foi de $50,3 \mathrm{~kg}$ e o de gestaçōes gemelares foi de $20,4 \mathrm{~kg}$ (significativamente menor).

Potros de ambos os sexos, mantidos em regime nutricional elevado, e que tiveram a sua altura mensurada desde o nascimento até o $1^{\circ}$ ano de vida, não apresentaram diferença entre sexos, embora tenha sido observada uma tendência a um maior tamanho para os machos (Grenn", 1969).

Segunck Jeffcout ${ }^{7}$ (1972), a primeira ingestão do colostro (xorre em módia aos 65 minutos após o nascimento e após a ingestão eles caminham, ou permanecem parados, ainda em equilibrio instável. Dentro de uma hora em média passam a apresentar sinais de suave dor abdominal e inicia-se a passagem do mecônio. Sabe-se que, além de prover o potro de imunoglobulinas circulantes, o colostro tem efeito benéfico ao carrear protetores do trato gastrointestinal e fomecer-lhe o complemento e a lactoferrina, aumentanko as suas defesas (LeBlanc", 1990). Simmen et al. ${ }^{18}$ (1990) alimentaram três grupos de leitões recém-nascidos com colostro, leite e lactose $5 \%$ e $\propto$ sacrificaram 24 horas após: como resultado observaram que o colostro ou leite produziram um crescimento significativo do epitélio intestinal dos recém-nascidos. Ulshen et al. ${ }^{20}$ (1991) afirmam que fatores tróficos presentes no leite são mediadores potenciais para o rápido crexcimento do epitélio intestinal do neonato. Kelly et al. ${ }^{\text {R }}$ (1993) observaram o mesmo efeito sob o epitélio intestinal de leitões recém-nascidos com o colostro.

A primeira descrição das fezes fetais foi realizada por Aristóteles, que utilizou a palavra grega mekonion, com o significado de "semelhante ao ópio", sugerindo que esta substância mantinha o feto em estado de sono no útero (Bergman', 1983). Na maioria dos casos, logo apús o parto, e dentro das poucas horas seguintes, os potros apresentam sinais de esforço e eliminam o mecônio sem dificuldade. Geralmente a postura durante o a to de defecar segue o padrão do adulto, embora alguns possam curvar-se na posição de miç̧ão (Rossdale; Ricketts ${ }^{17}, 1980$ ). O objetivo deste trabalho foi a obtenção de refenenciais práticos relacionaxass ao períxdo gestaxional, ao pós-parto, puerpério e ao potrinho. em virtude da carência de parâmetros obtichos em nosso ambiente.

\section{MATERIAL E MÉTODO}

No período compreendido entre julho de 1983 e novembro de 1992 foram observados trezentos e noventa partos em eqüinos da raça Puro-Sangue de Corrida, alojados no Haras Santa Maria de Araras, localizado a $25^{\circ} 31^{\prime}$ de latitude sul e $49^{\circ} 10^{\prime}$ de longitude oeste. São Jose dos Pinhais, Paraná.

Foram consideradas as seguintes variáveis:
1. Idade gestacional: período compreendido entre a ovulação e a expulsão completa do potro, en dias.

2. Tempo para ruptura do cordão umbilical: período compreendido entre a expulsão completa do pouro e a ruptura do cordão umbilical. em minutos.

3. Tempo para a apresentação de reflexos de succão, em minutos.

4. Tempo para levantar: período compreendido entre a expulsão completa do potro e o momento em que ele levantou pela primeira vez. em minutos.

5. Tempo para mamar: período compreendido entre a expulsão completa do potro e o momento em que mamou pela primeira vez, em minutos.

6. Tempo para a eliminação do mecônio: período compreendido entre a expulsão completa do potro e o momento em que houve a eliminação do mexônio. em minutos.

7. Sexo.

8. Peso do potro, em quilos, verificado nas primeiras 24 horas de vida.

\section{Peso de placenta, em quilos.}

10. Altura, em centímetros.

Observe-se que o manejo e o nivel nutricional aos quais estes animais estavam submetidos foram elevados e constantes e que potros com qualquer tipo de problema, comportamento alterado, que tenham sido submetidos a aleitamento artificial ou outra intervenção. e placentas corn qualquer tipo de alteração, foram desconsiderados.

A metodologia estatística incluiu a análise de correlação e regressão, análise de variância, e Teste F (Stell; Torrie ${ }^{19}$, 1980).

\section{RESULTADOS}

\section{Considerando-se o sexo dos potros}

O percentual de potros foi de $49,17 \%$ e o de potrancas de $50,83 \%$. O período médio de gestação de potros foi de 333,4 dias. variando entre 315-350 dias e, para as potrancas, uma média de 335,2 dias, variando entre 318-360) dias (Tab. 1). A média para levantar pela primeira vez foi de 53.5 minutos com amplitude entre 20 e 143 minutos pós-parto para os machos, e média de 46,1 minutos com amplitude entre 15 e 130 minutos para as fêmeas, havendo diferença entre os sexos ( $p<0,0027$ ) para levantar. Verificou-se que $17(10,89 \%)$ produtos machos levantaram nos primeiros 30 minutos e $95(60,89 \%)$ entre 30 e 60 minutos pós-parto. Quanto às potrancas, $42(24,85 \%)$ levantaram dentro de 30 minutos e 94 $(55,62 \%)$ entre 30 e 60 minutos pós-parto, logo $80,47 \%$ delas estavam de pé na $1^{\text {a }}$ hora pós-parto (Fig. 1).

O tempo para mamar pela primeira vez variou entre 28 e 245 minutos para os machos, média de 98.7 minutos e para as fêmeas entre 37 e 240 minutos, média de 92,7 minutos.

Os pesos das placentas dos produtos machos oscilaram entre 2,7 e 10 quilos, média de $5,9 \mathrm{~kg}$ e os pesos das placentas das fêmeas entre 2,4 e $10 \mathrm{~kg}$, média de $5,8 \mathrm{~kg}$. O peso dos produtos machos variou entre 34 e 70 quilos, média de $51,7 \mathrm{~kg}$, e das fêmeas entre 33 e 66 quilos, média de $50.4 \mathrm{~kg}$. A altura dos produtos do sexo masculino foi em média $100.5 \mathrm{~cm}$, com amplitude de 92 a 109 cm, e, para as fêmeas, em média de $99,4 \mathrm{~cm}$. com amplitude de 85 a 
$109 \mathrm{~cm}$. Verificou-se ainda que os potros eram significativamente mais altos do que as potrancas $(p<0,017)$.

\section{Período de adaptação dos potros}

O tempo para a ruptura nattural do cordão umbilical oscilou desde a ruptura imediata até um tempo máximo de 5() minutos, com a média de 6.2 minutos. O reflexo de sucção manifestou-se entre os l0 e os 95 minutos após o parto, e em média aos 36 minutos (Tab. 2).

Os potrinhos levantaram em média aos 49 minutos, com um período mínimo de 15 minutos até um extremo de 143 minutos (Tab. 2). Observou-se que 273 deles $(78,67 \%)$ levantaram em até 6) minutos e $90.48 \%$ deles o fizeram em até 90 minutos (Figura 2).
E todos levantaram em até 2 horas e 23 minutos.

O tempo entre o parto e a primeira mamada apresentou variaçōes extremas entre 28 e 245 minutos, sendo a média de 94 minutos. A eliminação do mecônio ocorreu entre 30) e 285 minutos após o parto, com uma média de 127,4 minutos (Tab. 2), ou seja, em média 30 minutos após a $1^{2}$ mamada.

Considerando-se o momento da primeira mamada, 284 (82.55\%) produtos mamaram em até 2 horas pós-parto. concentrando-se a maior incidência da ocorrência no período entre 30 e 120 minutos pós-parto (Fig. 3).

O peso médio dos produtos foi de $51,(24 \mathrm{~kg}$. variando entre 33 a 70 quilos, e altura média de $99,6 \mathrm{~cm}$. variando entre $85 \mathrm{~cm} \mathrm{e}$ máxima de $109 \mathrm{~cm}$.

TABELA 1

Duraçāo da gestaçōo [DG], tempo para levantar (TL), para mamar (TM). pesos das placentas (PPL) e dos potros (PP), assim como a altura (A) dos potros, observados em 286 partos no período de $1^{\circ}$ de julho de 1983 a 25 de novembro de 1992, no Haras Santa Maria de Araras, Sāo José dos Pinhais, PR.

\begin{tabular}{|c|c|c|c|c|c|c|c|c|}
\hline Parâmetro & \multicolumn{3}{|c|}{ potros $(49,17 \%)$} & & \multicolumn{4}{|c|}{ potros $(50,83 \%)$} \\
\hline & $\mathrm{n}$ & $x$ & $\sigma$ & amplitude & $\mathrm{n}$ & $x$ & $\sigma$ & amplitude \\
\hline DG (dias) & 55 & $333,4^{a}$ & $\pm 7,7$ & $315-350$ & 54 & $335,2^{a}$ & $\pm 9,10$ & $318,0-360$ \\
\hline$T L^{*}(\min )$ & 158 & $53,5^{a}$ & $\pm 24,3$ & $20-143$ & 169 & $46,1^{b}$ & $\pm 20,30$ & $15,0-130$ \\
\hline TM (min) & 159 & $98,7^{a}$ & $\pm 40,4$ & $28-245$ & 163 & $92,7^{a}$ & $\pm 39,10$ & $37,0-240$ \\
\hline PPL (kg) & 171 & $5,9^{\mathrm{a}}$ & $\pm 1,3$ & $2,7-10$ & 172 & $5,8^{\mathrm{a}}$ & $\pm 1,29$ & $2,4-10$ \\
\hline$P P(k g)$ & 141 & $51,7^{a}$ & $\pm 6,8$ & $34-70$ & 145 & $50,4^{a}$ & $\pm 7,20$ & $33,0-66$ \\
\hline$A^{* \star}(\mathrm{cm})$ & 139 & $100,5^{a}$ & $\pm 3,6$ & $92-109$ & 145 & $99,4^{a}$ & $\pm 4,20$ & $85,0-109$ \\
\hline
\end{tabular}

Na mesma linha, médias seguidas de letras diferentes pelo teste $F$, ao nivel representado

$p<0,00027 ; F=9,17$

** $p<0,017 ; F=5,7$

$n=$ número de observações $x=$ média $\sigma=$ desvio padrão

Figura 1

Distribuiçāo percentual dos potrinhos conforme o sexo em funçāo do momento em que levantaram pela primeira vez, em 325 observaçōes no periodo de $1^{\circ}$ de julho de 1983 a 25 de novembro de 1992. São José dos Pinhais, PR.

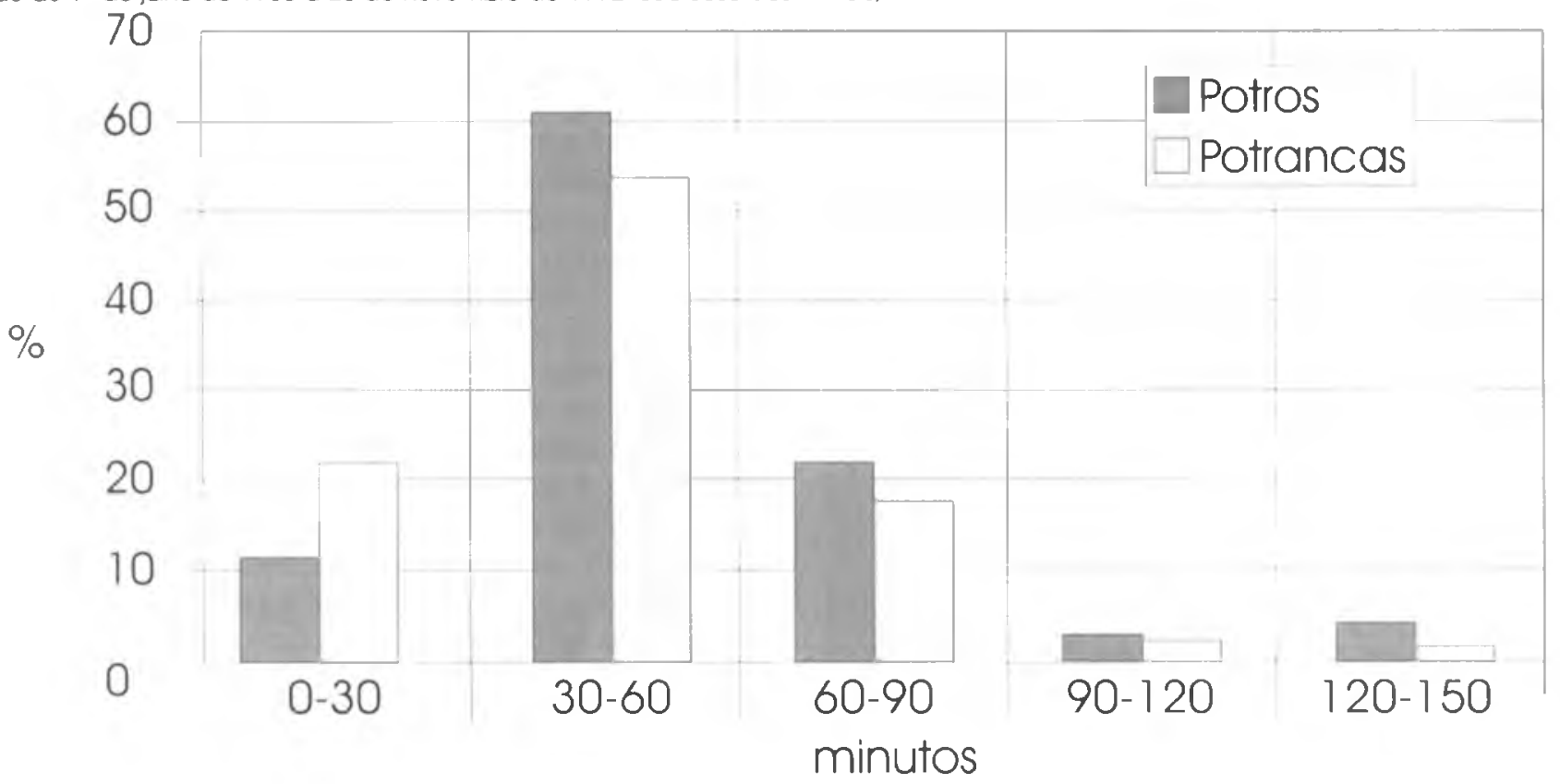


KIIRTZ FILHO. M.; DEPRÁ. N.M.: ALDA. J.L.; CASTRO, I.N ; CORTE. F.D.; SILVA, C.A.M. Parâmetros fisiologicos e etológicos do potro reccém-nascido, na raça puro-sanguc de corrida. Braz. J. vet. Res. anim. Sci., São Paulo, v.34, n.2, p.103-108, 1997.

\section{Tabela 2}

Descrição dos valores médios do tempo para a rupłura do cordão umbilical (RU), para apresentaçāo do reflexo de sucçāo (RS), para levantar (TL). para mamar (TM) e para eliminação do mecônio (TE), em 350 partos assistidos no período de $1^{\circ}$ de julho de 1983 a 25 de novembro de 1992 , no Haras Santa Maria de Araras, São José dos Pinhais, PR

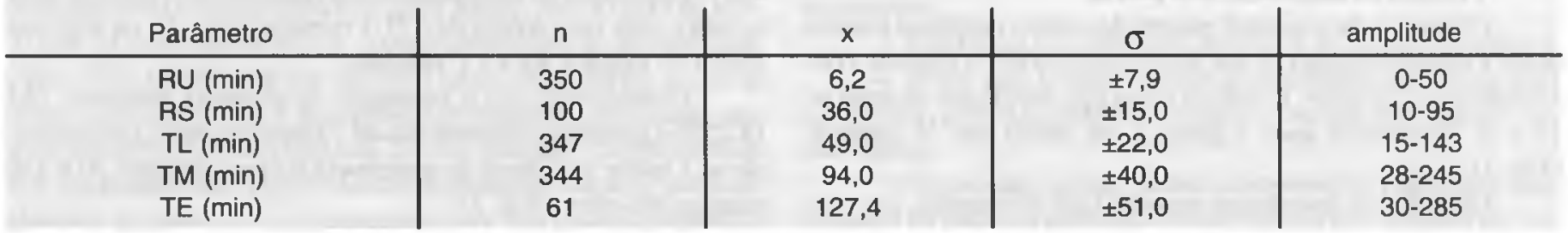

\section{Figura 2}

Distribuiçăo percentual do momento em que os potros levantaram pela primeira vez em relação ao horário do parto, em 347 observaçōes no período de $1^{\circ}$ de julho de 1983 a 25 de novembro de 1992. Sōo Jose dos Pinhais, PR.

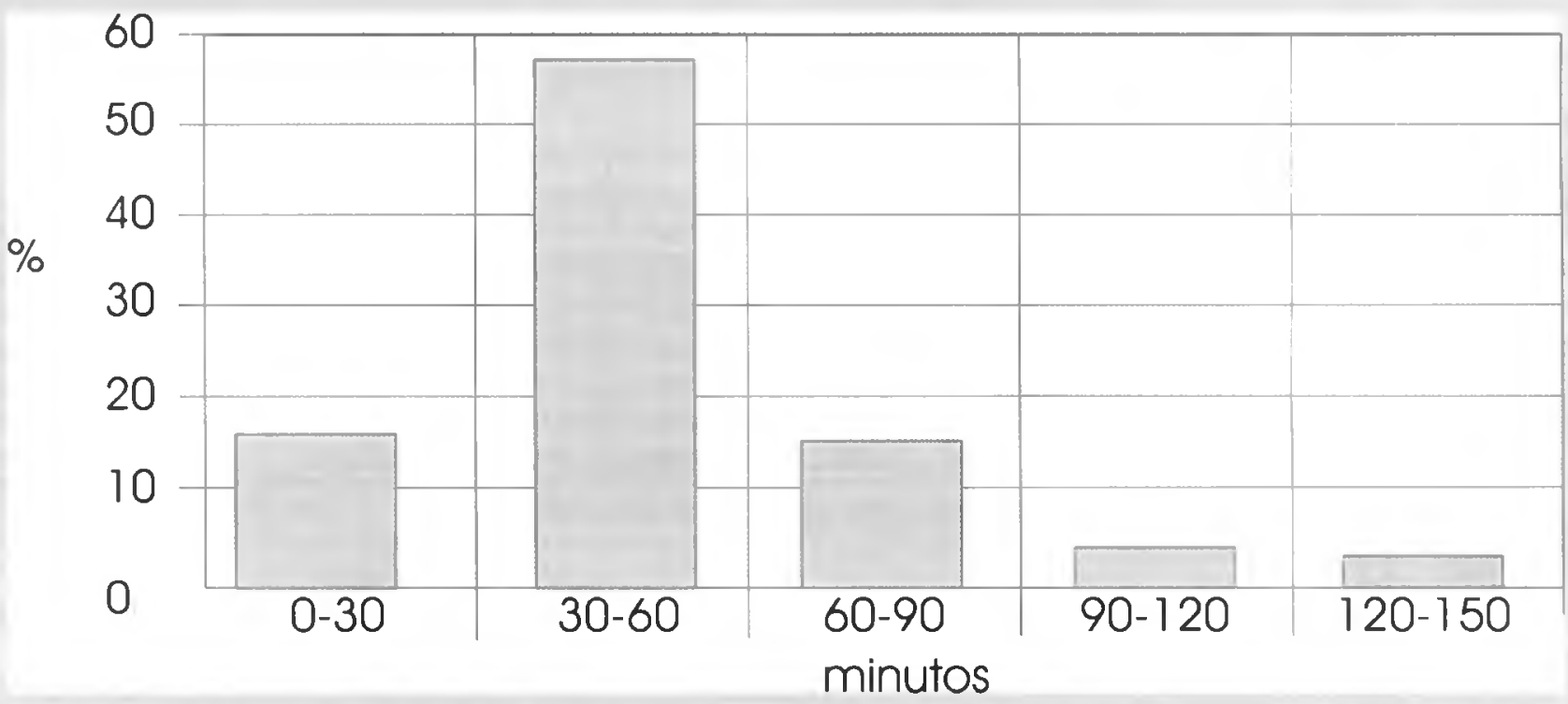

Figura 3

Distribuiçāo percentual do momento em que os potros mamaram pela primeira vez em relaçāo ao horário do parto, em 344 observaçāes no periodo de $1^{\circ}$ de julho de 1983 a 25 de novembro de 1992. São Jose dos Pinhais. PR.

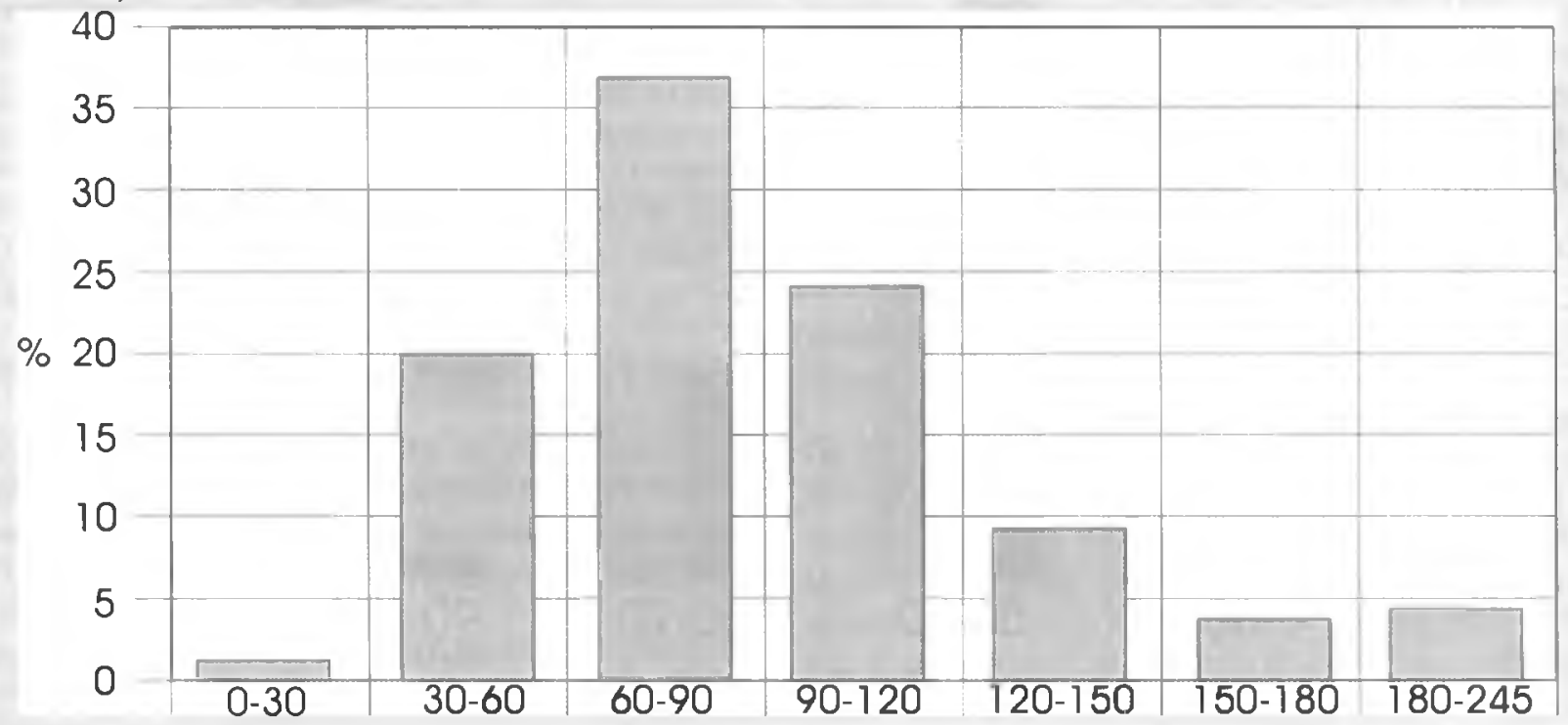




\section{DISCUSSÃO}

Verificou-se nos machos uma média de 53,5 minutos para levantar e nas fêmeas 46,1 minutos (Tab. 1 e Fig. 1); essa diferença é significativa $(p<0,002)$. Os produtos de ambos os sexos apresentavam boas condiçōes físicas no momento do parto e não se observou diferença significativa ente os pesos de potros e potrancas. Embora alguns autores (Whitwell; Jeffcott ${ }^{21}, 1975$; Campitelli et al. $.^{2}, 1982 / 1983$ ), atribuam ao menor peso o fator determinante para alguns indivíduos levantarem-se mais precocemente do que outros; aqui isto não foi verificado.

Quanto ao momento para o produto mamar pela primeira vez observou-se um tempo médio de 94 minutos (28-245 minutos), não se encontrando diferença significativa entre os sexos. Ou seja, embora em pé mais tardiamente, os machos habilitamse a mamar no mesmo período de tempo das fêmeas que se levantaram mais cedo (vide Figs. I e 3). Observou-se que $80 \%$ dos produtos mamaram até 2 horas após o parto e a maioria entre os 60-120 minutos. Após a primeira mamada o elo entre filho e mãe está aparentemente estabelecido, sendo que algns potros levam até 4 horas para estabelecer profundamente este vínculo. Os dados aqui obtidos corroboraram os de Rossdale ${ }^{13}$ (1967), Jefcott ${ }^{3}(1972)$, e Whitwell; Jeffcott ${ }^{21}$ (1975) que observaram uma tendência igual porém com uma variação um pouco mais ampla.

Observa-se que o peso médio dos produtos machos foi de $51,7 \mathrm{~kg}(34-70 \mathrm{~kg})$ e o das fêmeas de $50.4 \mathrm{~kg}(33-66 \mathrm{~kg})$, valores semelhantes aos achados por Rossdale ${ }^{14}$ (1968a), Whitwell; Jeffcott ${ }^{21}$ (1975) e Platt "(1978). Quanto à altura dos produtos (Tab. 1), observa-se que os do sexo masculino apresentaram-se um pouco mais altos $x=100,5 \mathrm{~cm}(92-109 \mathrm{~cm})$ do que os do sexo feminino $x=99,4 \mathrm{~cm}(85-109 \mathrm{~cm})$; apesar dessa diferença ser significativa $(p<0,017)$, deve refletir apenas características corporais inerentes ao sexo. No entanto, essa diferença não foi observada noutras populaçōes (Green ${ }^{4}, 1969$ ).

A ruptura natural e espontânea do cordão umbilical ocorreu em média aos 6,2 minutos após o parto, com uma amplitude desde imediatamente até 50 minutos depois do parto (Tab. 2). O cordão umbilical, constituído, logo abaixo do epitélio, de tecido conjuntivo (geléia de Warthon) e fibras colágenas, de duas artérias e da veia umbilical, rompeu-se sempre em sua porção mais frágil e estreita, distante ao redor de $3 \mathrm{~cm}$ do abdômen, local de ruptura natural por tração no potro recém-nascido. A ruptura imediata do cordão umbilical e a privação do sangue placentário que, supostamente, pertenceria ao potro não influenciou negativamente o aspecto clínico e o comportamento posterior dos produtos; diferentes observadores também notaram que a falta de sangue placentário não alterou o comportamento dos potros (Doarn et al. ${ }^{3}, 1987$ ). Os principais sintomas de potros recémnascidos doentes são letargia, ausência do reflexo de sucção, inabilidade para parar e manter a posição de mamar (Rossdale ${ }^{15}$, 1968b). Por isto o conhecimento dos parâmetros normais é de extrema importância

O reflexo de sucção apareceu nos potros aproximadamen- te 36 minutos após o parto (10-95 minutos), (Tab. 2); alguns autores citam-no ocorrendo já nos primeiros minutos pós-parto (Mahaffey; Rossdale ${ }^{10}, 1957$ ), porém pode-se afirmar que a sua manifestação até 95 minutos após o parto não significa alteração patológica. Alguns potros só manifestam o reflexo de sucção após contato mais intenso com a mãe. Rossdale ${ }^{17}$ (1967) observou o reflexo de sucção presente dentro de meia a uma hora após o parto; esses dados são semelhantes aos aqui obtidos e indicam ser necessário decorrer um certo tempo após o parto para que seja posta em ação a cadeia de reflexos nervosos responsável pelo processo.

Em 347 partos, observou-se que os animais levantaram, em média, pela primeira vez, aos 49 minutos após o nascimento (variando entre 15-143 minutos); $95 \%$ dos produtos levantaram até 90 minutos e $77 \%$ deles levantaram até 60 minutos após o parto. A capacidade de manter-se em pé é um indicativo da saúde do potrinho. Pelos casos aqui observados $(n=347)$ verificouse que, normalmente, eles levantaram-se dentro de 2 horas e 23 minutos após o nascimento e que, caso não levantem dentro deste período, devem ser considerados desajustados. Esses resultados são corroborados pelos de Rossdale ${ }^{13}$ (1967) e Campitelli et al..$^{2}(1982 / 1983)$.

O tempo para eliminação do mecônio (Tab. 2) foi em média de 127,4 minutos após o parto (30-285), não havendo diferença significativa entre os sexos. Embora não tenha havido relação estatística significativa entre a primeira mamada e a eliminação do mecônio, esta ocorreu em média 30 minutos após a primeira mamada. O colostro tem efeito reconhecido na promoção do desenvolvimento intestinal pós-parto (Simmen et al. 1990) e na maturação do intestino delgado, em leitões (Ulshen et al. ${ }^{20}$, 1991; Kelly et al. ${ }^{\mathrm{B}}$, 1993). Jeffcott ${ }^{7}$ (1972) e LeBlanc ${ }^{9}$ (1990) observaram um efeito estimulante do colostro à motilidade gastrointestinal. Aqui, em virtude do pequeno número de observações $(n=61)$ (Tab. 2), isto não foi comprovado estatisticamente. Sugere-se que esta ação sobre a motilidade gastrointestinal, por si só, seria suficiente para contraindicar aplicações profiláticas de laxantes e enemas nos potros logo após o parto. Potros sadios mamando colostro de boa qualidade tendem a não apresentar sintomas de retenção de mecônio. $O$ controle clínico do potro recém-nascido aliado à análise da qualidade do colostro permitiriam evitar o uso "profilático" de laxantes pósparto. Cavalos selvagens ou os criados extensivamente não apresentam evidência desta patologia ou ela é muito rara. É possível ainda que a manipulação intensa da égua e do potro provoquem sobrecargas de tal ordem que possam interferir com um adequado funcionamento gastrointestinal e com a produção de colostro.

\section{CONCLUSÕES}

As fêmeas levantaram pela primeira vez mais cedo do que os machos e não houve diferença de peso entre os sexos. A primeira mamada ocorreu em um período de tempo semelhante para ambos os sexos. A ruptura imediata do cordão umbilical não influenciou negativamente o aspecto clínico posterior do potro. A eliminação do mecônio ocorreu em média 30 minutos após a primeira mamada. 


\section{SUMMARY}

Three hundred and ninety deliveries of Thoroughbred mares were observed between July, 1983 and November, 1992, with the aim of determining physiologic parameters regarding the foal. The average time for the umbilical cord rupture was 6,2 minutes. The suckling reflex was observed 36 minutes after delivery. Mean time for standing was 49 minutes, and the ones which stood within 2:23 hours didn't have adaptation problems. Mean time for the first suckling was 94 minutes, and 82,55\% did it within 2 hours after birth. Elimination of meconium occurred at 127.4 minutes after delivery, 30 minutes after first suckling.

\section{REFERÊNCIAS BIBLIOGRÁFICAS}

1-BF.RGMAN. R.V. Retained meconium. In: ROBINSON, N. E. Current therapy in equine medicine. Philadelphia, W.B. Saunders, cap. 5. 1983, p.260-2.

2-CAMPITFI I.I.S., CARENZI. C., VERGA. M. Factors hich influence parturition in the mare and development of the foul. Applied Animal F.thology, v. 9. p. 7-14. 1982/1983.

3-IX)ARN. R.T.. THREFAI.L. W.R. KI.INE. R. Limbilical blood flow and the effects of premature severunce in the neonatal horst. Theriogenology. v.28. n.6. p. 789-80(0), 1987.

4-GRFEN. I) A A study of growth rale in thoroughbred foals. British Veterinary Journal , v. 125, n. 10, p.539-46, 1969.

5-HINT7., H.F., HINT\%, R.L., LEIN. D. H.. VLECK, L. D. L ength of gestation periods in thorcughbred nares. Journal of Kquine Medicine and Surgery, v.3, n.6. p.289-92. 1979a.

6-HINT7. H.F. HINT7., R.L., VLECK. L. D. Growth rate of thoroughbreds, effect of age of dame year and month of birth. and sex of foal. Journal of Animal Science, v.48, 11.3, p.480-7, 1979b.

7-JEFFCOTT, L.R. Observation on parturition in crossbred pony mares. Equine Veterinary Journal. v.4, n.4. p.209-13. 1972.

8-KEI.I.Y. D.. KING. T.P., McFADYEN, M., COUTTS, A.G. Effect of preclosure colostrum intake on the development of the intestinal epithelium of artificially reared piglets. Biology of the Neonate. v.64, n.4, p.235-244. 1993.

9-LeBLANC. M.M. Immunologic Considerations. In: KOTERBA. A. M.. DRUMMOND. W. H.. KOSCH. P. C. Fquine clinical neonatology. Philadelphia. Lea \& Febiger, cap. 16, 1990, p.275-94.

10-MAHAFFEY, L. W.. ROSSIDALE. P.I). Convulsive and allied syndromes in new-bom foals. Veterinary Record, v.69 (part. 2). 11.49. p.1277-86, 1957.

II-PLA'TT. H. Growth and maturity in the equine fetus. Journal of the Royal Seciety of Medicine. v.71, p.658-61, 1978.

12-ROPIHA, R.T., MATTHEWS, R.G.. BUTTERFIEL.D, R.M.. MOSS F.P., MCFAIDIEN, W.J. The duration of pregnancy in thoroughbred mares. Veterinary Recurd, v.84, л.22, p.552-55, 1969.

13-ROSSDAL,E, P. D. Clinical studies on the new born thoroughbred foal. I Perinatal behaviour. British Veterinary Journal, v.123, p.470-81, 1967.

14-ROSSIDAL.E, P.D. Discussion of paper on "abortion in mares". Veterinary Recurd, v.82, n.24. p.687.9. 1968 a.

15-ROSSIDAI.F, P.D. Abnonnal perinatal behaviour in the thoroughbred horse. British Veterinary Journal, v. 124, n. 12, p.540-53, 1968h.

16-ROSSI)AI.E. P.D.. MAHAIIZY. L.W. Parturition in thoroughbred mare with particular reference to blood deprivation in the new-borm. Veterinary Record. v. 70, n.7, p. $142-52,1958$

17-ROSSI)ALE. P.D.. RICKETTS. S. W. F.quine studies farm medicine. London. Bailliere Tindall, 1980, p.564.

I8-SIMMEN, F.A. CERA, D R., MAHNN, D.C. Stimulation by colostrum or mature milk of gastrointestinal tissue development in newhom pigs. Journal of Animal Science, v. 68, n. 11, p. 3596-603, 1990.

19-STEEI. R.G.D.. TORRIE, J.H. Principles and procedures of statistics, a biometrical approach 2. ed. New York. Mc Graw-Hill, 1980. 63.3p.

20-ULSHEN. M.H.. I.FCCE, J.G., STILES, A.D., LYN - COOK, L.E. Effects of nursing on growth and development of smal bowell mucosa in new born piglets. Pediatric Research. v..30, n.t, p.337-41. I\%91.

21-WHITWELI. K.E.. JEFFCOTT, I.B. Morphological studies on the fetal membrines of the nonnal singleton foal at term. Research in Veterinary Science. v.19. n. I. p.H-55. 1975.

Recebido para publicação: 29/09/95 Aprovado para publicação: 11/07/96 